\title{
Properties of Co-Ferrite Nanoparticles Synthesized by Thermal Decomposition Method
}

\author{
Young Woo Oh* and J. P. Liu ${ }^{1}$ \\ Dept. of Advanced Materials Engineering, Kyungnam University, Masan 631-701 Korea \\ ${ }^{1}$ Department of Physics, University of Texas at Arlington, TX76019, USA
}

(Received 8 August 2006)

\begin{abstract}
Co-ferrite nanoparticles have been synthesized by the decomposition of iron(III) acetylacetonate, $\mathrm{Fe}(\mathrm{acac})_{3}$ and Co acetylacetonate, $\mathrm{Co}(\mathrm{acac})_{2}$ in benzyl/phenyl ether in the presence of oleic acid and oleyl amine at the refluxing temperature of $295^{\circ} \mathrm{C} / 265{ }^{\circ} \mathrm{C}$ for $30 \mathrm{~min}$. before cooling to room temperature. Particle diameter detected by PSA can be turned from $4 \mathrm{~nm}$ to $20 \mathrm{~nm}$ by seed-mediated growth and reaction conditions. Structural and magnetic characterization of Co-ferrite were measured by use of HRTEM, SAED (selected area electron diffraction), XRD and SQUID. The as-synthesized Co-ferrite nanoparticles have a cubic spinel structure and coercivity of $20 \mathrm{~nm} \mathrm{CoFe} \mathrm{O}_{4}$ nanoparticles reached $1 \mathrm{kOe}$ at room temperature and $18 \mathrm{kOe}$ at $10 \mathrm{~K}$.
\end{abstract}

Key words : Co-ferrite nanoparticles, coercivity, seed-mediated growth, forming gas

\section{Introduction}

The current and potential applications for nanoparticles are growing and cover a broad range of markets which is estimated to be 1000 times in 2010 compared with in $2005[1,2]$.

The cubic spinel structured $\mathrm{CoFe}_{2} \mathrm{O}_{4}$ is well known to oxide magnetic materials, and nowadays its nanoprticles may have numerous applications as soft and hard magnetic materials for bio, mechanical and electronic fields.

The synthesis of magnetic nanoparticles such as Fe, $\mathrm{FePt}$, Co-ferrite, magnetite etc. has scientific and technical interest [3-6].

A wide variety of different techniques are used to synthesize magnetic nanoparticles; the chemical method, mechanical size reduction, gas phase synthesis etc. All of these have their own merits and faults.

The synthesis of Co-ferrite nanoparticles was reported by many researchers, Moumen etc. obtained 2-5 nm Coferrite nanoparticles by control the concenturation of reactants using oil-in-micelles [2]. Chinnasamy etc. [3] synthesized 8 40, 7 100 nm Co-ferrite particles and reported average switching field $\left(H_{\mathrm{p}}\right)$, magnetic crystalline constant $(K)$ and coercivity $\left(H_{\mathrm{c}}\right)$ at room temperature. In

*Corresponding author: Tel: +82-55-249-2696,

Fax: +82-55-248-5033, e-mail: ceramoh@kyungnam.ac.kr magnetite nanoparticles, Sun etc. synthesized monodisperse 4 and $6 \mathrm{~nm} \mathrm{Fe}_{3} \mathrm{O}_{4}$ particles, if phenyl ether was used as solvent, $4 \mathrm{~nm} \mathrm{Fe}_{3} \mathrm{O}_{4}$ nanoparticles were separated, while the use of benzyl ether led to $6 \mathrm{~nm} \mathrm{Fe}_{3} \mathrm{O}_{4}$ because of different boiling point $[4,5]$.

Here we report a simple chemical synthesis of Coferrite nanoparticles with average $2 \mathrm{~nm}$ size in diameter and a seed-mediated growth method to make larger Coferrite nanoparticles.

\section{Experiment}

To prepare $\mathrm{CoFe}_{2} \mathrm{O}_{4}$ nanoparticles, we used $\mathrm{Fe}(\text { acac })_{3}$ $($ acac $=$ acetylacetonate $)$ and $\mathrm{Co}(\mathrm{acac})_{2}$ without further purification. $\mathrm{Fe}(\mathrm{acac})_{3}$ and $\mathrm{Co}(\mathrm{acac})_{2}$ were purchased from Sigma-Aldrich Co. Oleic acid and oleylamine are necessary for the formation of particles.

The synthetic experiments were carried out under $\mathrm{Ar}$ atmosphere, $\mathrm{Fe}(\mathrm{acac})_{3}(2 \mathrm{mmol}), \mathrm{Co}(\mathrm{acac})_{2}(1 \mathrm{mmol})$, 1,2-hexadecanediol $(10 \mathrm{mmol})$ and benzyl ether $(20 \mathrm{ml})$ were mixed in a flask equipped with a $\mathrm{Ar}$ in/outlet and a thermal probe. The mixture was heated to $100{ }^{\circ} \mathrm{C}$ by $5{ }^{\circ} \mathrm{C}$ per min. After refluxing for $20 \mathrm{~min}$. at $100{ }^{\circ} \mathrm{C}$, added oleic acid $(6 \mathrm{mmol})$ and oleylamine $(6 \mathrm{mmol})$ as surfactants, and refluxed for $30 \mathrm{~min}$. at $265^{\circ} \mathrm{C}$.

Particle size of as-synthesized powders was measured by PSA (Particle Size Analyzer, NanoTrac 250). The 
morphology and phase identification of Co-ferrite nanoparticles were analyzed by use of HRTEM and XRD. Magnetic studies were carried out using VSM and SQUID magnetometer with temperature from 10 to 300 $\mathrm{K}$.

\section{Results and Discussion}

Benzyl ether and Phenyl ether were used as solvents. In the case of benzyl ether, we can raise the fluxing temperature because of high boiling temperature than phenyl ether, but the fluxing temperature of last step in this procedure didn't affect the size of as-synthesized particles.

The particle size of as-synthesized powders measureded by PSA was average $2 \mathrm{~nm}$. Figure 1 shows particle size distribution of as- synthesized Co-ferrite nanoparticles measured by PSA.

Figure 2 shows the TEM images of the $10 \mathrm{~nm}$ and 20 $\mathrm{nm}$ Co-ferrite nanoparticles grown by seed-mediated growth method. Seed-mediated process was carried out by adding the as-synthesized nanoparticles (average $2 \mathrm{~nm}$ shown in Figure 1), 4, $8 \mathrm{~nm}$ etc. as seeds in the same starting reagents and heated, and particle size increased $\sim 2 \mathrm{~nm}$ or more in each seed-mediated reaction. This method has

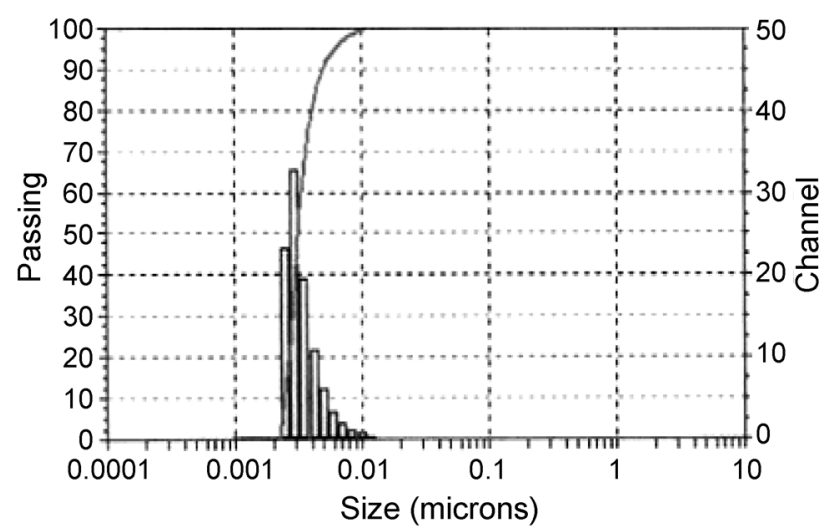

Fig. 1. Particle size distribution of as-synthesized Co-ferrite nanoparticles measured by PSA.
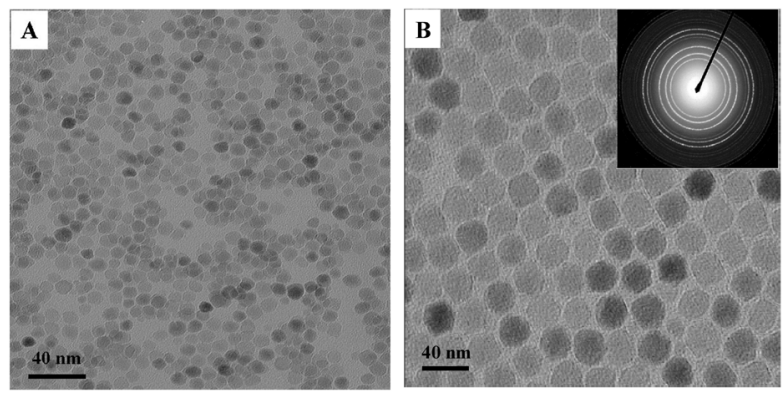

Fig. 2. TEM images and SAED patterns of Co-ferrite nanoparticles. (A) $10 \mathrm{~nm}$ (B) $20 \mathrm{~nm}$.

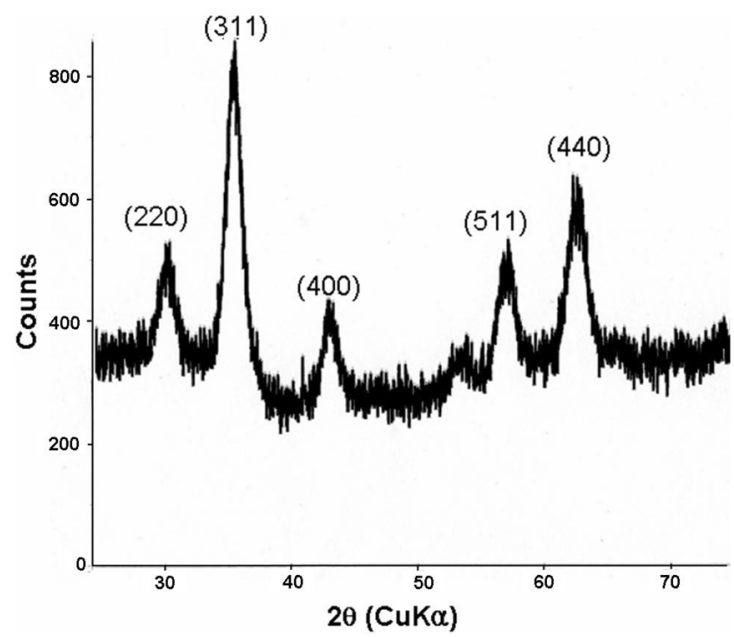

Fig. 3. XRD pattern of $10 \mathrm{~nm}$ Co-ferrite nanoparticles.

been recently applied to larger nanoparticles synthesis, through slow, continuous nucleation and fast, autocatalytic surface growth $[7,8]$.

Figure 3 shows the XRD pattern of $10 \mathrm{~nm}$ Co-ferrite particles grown by seed-mediated growth method from 8 $\mathrm{nm}$ particles. It was found that all the peaks of nanoparticles synthesized by seed-mediated growth method
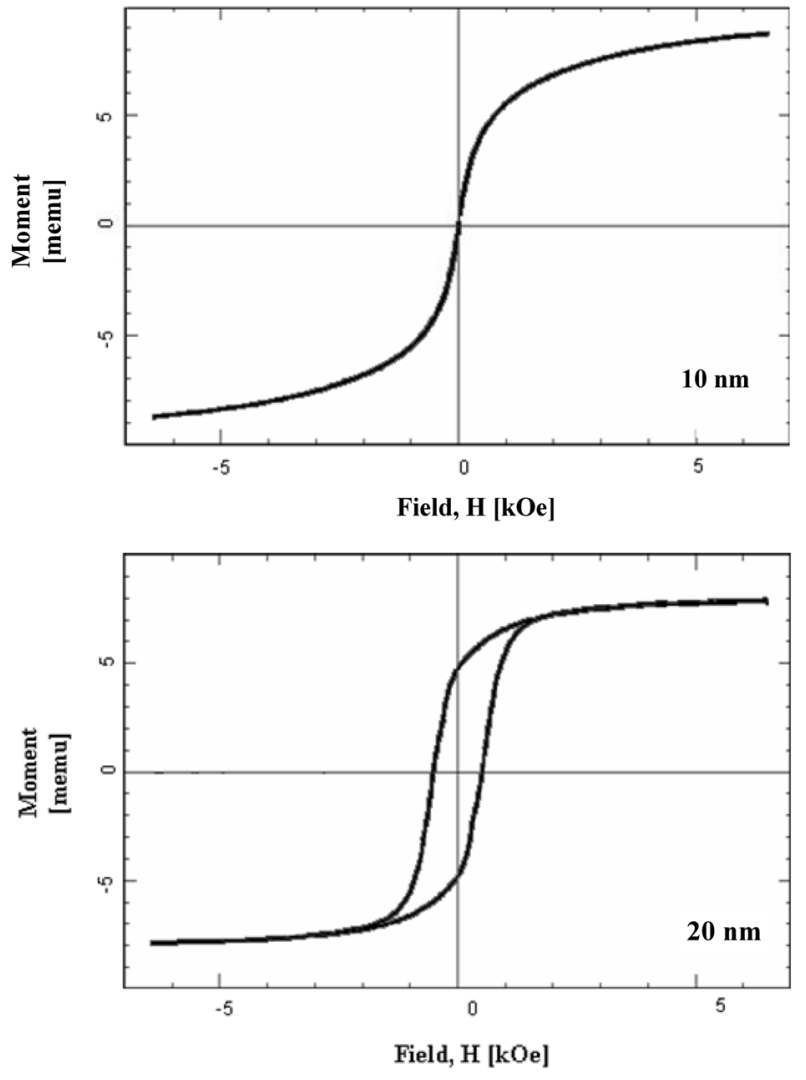

Fig. 4. Hysteresis loops of Co-ferrite nanoparticles at room temperature. 


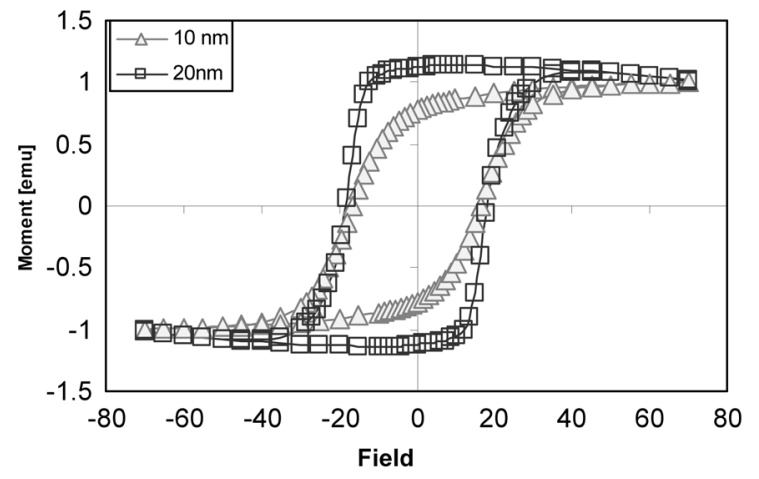

Fig. 5. Hysteresis loops of Co-ferrite nanoparticles at $10 \mathrm{~K}$.

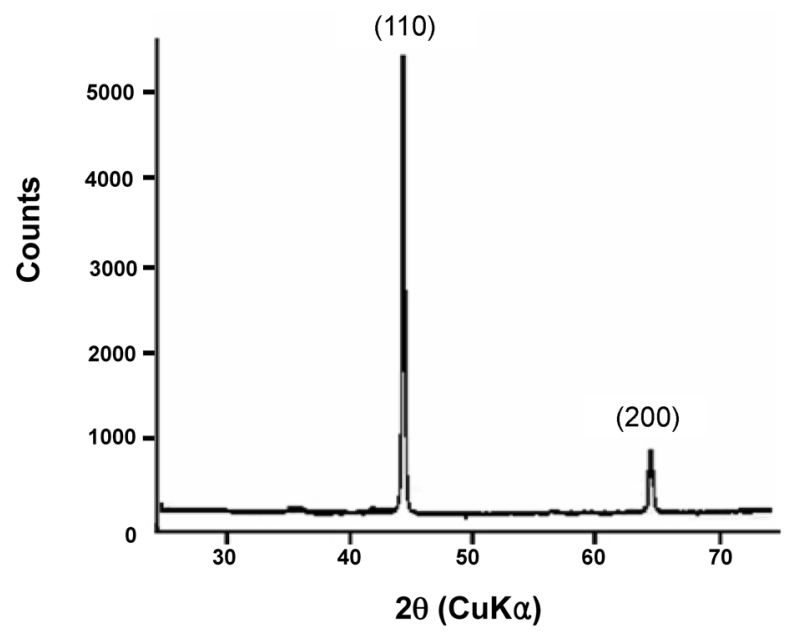

Fig. 6. XRD pattern of nanoparticles after annealing at $600{ }^{\circ} \mathrm{C}$ for $30 \mathrm{~min}$. under forming gas.

were appeared typical patterns of the cubic structured Coferrite.

We can see the magnetic values of particles in Fig. 4 that the coercivity $\left(H_{\mathrm{c}}\right)$ on the hysteresis loop reveals 635 Oe and $1 \mathrm{kOe}$, respectively. And also Fig. 5 shows the coercive force of the same sized particles in Fig. 4, but at $10 \mathrm{~K}$ are 16.2 and $18.5 \mathrm{kOe}$, respectively, so at low temperature they all show strong magnetic behavior.

Cubic structured Co-ferrite transformed to cubic $\mathrm{FeCo}$ phase which has main (110) peak by annealing at $600{ }^{\circ} \mathrm{C}$ for $30 \mathrm{~min}$. in the $\mathrm{Ar}+\mathrm{H}_{2}$ forming gas and the resulting of annealing is shown in Figure 6. It provides that $\mathrm{FeCo}$ nanoparticles obtained by reduction of Co-ferrite can be applied to the exchange-coupled nanocomposite magnets such as $\mathrm{FePt} / \mathrm{FeCo}$ materials.

\section{Conclusion}

$2 \mathrm{~nm}$ sized Co-ferrite nanoparticles were synthesized by chemical process and grew to $10 \mathrm{~nm}, 20 \mathrm{~nm}$ particles by seed-mediated growth method. Structural and magnetic characterization of Co-ferrite were measured by use of HRTEM, SAED, XRD, VSM and SQUID. The as-synthesized Co-ferrite nanoparticles have a cubic spinel structure and coercivity of $10 \mathrm{~nm}, 20 \mathrm{~nm}$ Co-ferrites reached 626 Oe, $1 \mathrm{kOe}$ at room temperature and 16.2, $18.5 \mathrm{kOe}$ at 10 $\mathrm{K}$, respectively.

\section{Acknowledgement}

This work was supported by Kyungnam University as sabbatical at Dept. of Physics, University of Texas at Arlington in 2004.

\section{References}

[1] B. I. Lee, L. Qi and T. Copeland, J. Ceram. Proc. Res. 6(1), 31 (2005).

[2] N. Moumen and M. P. Pileni, Chem. Mater. 8, 1128 (1996).

[3] C. N. Chinnasamy, B. Jeyadevan, K. Shinoda, and K. Tohji etc., Appl. Phys. Lett. 83(14), 2862 (2003).

[4] S. Sun, H. Zeng, D. B. Robinson, S. Raoux, P. M. Rice, S. X. Wang and G. Li, J. Am. Chem. 126(1), 273-279 (2004).

[5] K. E. Elkins, T. S. Vedantam, J. P. Liu, H. Zeng, S. Sun, Y. Ding and Z. L. Wang, Nano Letters 3(12), 1467-1649 (2003).

[6] D. Li, N. Poudyal, V. Nadawana, Z. Jin, K. Elkins, J. P. Liu, J. Appl. Phys. 99, 08E912 (2006).

[7] H. Yu, P. C. Gibbson, K. F. Kelton, and W. E. Buhro, J. Am. Chem. Soc. 123, 9198 (2001).

[8] M. A. Watzky and R. G. Kinke, J. Am. Chem. Soc. 119, 10382 (1997). 